\title{
REVISTA
}

\section{FERMENTAÇÃO ANAERÓBICA NO CAFÉ ARÁBICA E SEU IMPACTO NO PERFIL SENSORIAL}

\section{ANAEROBIC FERMENTATION IN ARABICA COFFEE AND ITS IMPACT ON THE SENSORY PROFILE}

\author{
${ }^{1}$ Cristhiane Altoé Filete \\ ${ }^{2}$ Luiz Henrique Bozzi Pimenta de Sousa \\ ${ }^{3}$ Rogério Carvalho Guarçoni \\ ${ }^{4}$ Dério Brioschi Junior \\ ${ }^{5}$ João Paulo Pereira Marcate \\ ${ }^{6}$ Aldemar Polonini Moreli \\ ${ }^{7}$ Taís Rizzo Moreira \\ ${ }^{8}$ Willian dos Santos Gomes \\ ${ }^{9}$ Evandro de Andrade Siqueira \\ $1 *$ Lucas Louzada Pereira
}

\begin{abstract}
${ }^{1}$ Instituto Federal do Espírito Santo, Laboratório de Análise e Pesquisa em Café - LAPC. Venda Nova do Imigrante, Espírito Santo, Brasil. (anealtoe@gmail.com)

${ }^{2}$ BMP Farmers Coffee Consultoria e Comércio LTDA. Venda Nova do Imigrante - ES (luizhenriquebozzipimenta@gmail.com).

${ }^{3}$ Instituto Capixaba de Pesquisa, Assistência Técnica e Extensão Rural, Vitória, Espírito Santo, Brasil. (rogério.guarconi@gmail.com)

${ }^{4}$ BMP Farmers Coffee Consultoria e Comércio LTDA. Venda Nova do Imigrante - ES. (derio.brioschi@outlook.com)

${ }^{5}$ BMP Farmers Coffee Consultoria e Comércio LTDA. Venda Nova do Imigrante - ES. (joaopaulomarcate@hotmail.com)

${ }^{6}$ Instituto federal do Espírito, Departamento de Administração venda Nova do Imigrante-Es. (aldemarpolonini@gmail.com)

${ }^{7}$ Universidade Federal do Espírito Santo, Centro de Ciências

Agrárias, Jeronimo Monteiro-ES. (taisr.moreira@hotmail.com)

${ }^{8}$ Universidade Federal do Espírito Santo, Campus de Alegre, Alegre, Espírito Santo, Brasil.(gwill.bio@gmail.com) ${ }^{9}$ Instituto federal do Espírito, Departamento de Administração venda Nova do Imigrante-Es (evandro.siqueira@ifes.edu.br)

*Instituto Federal do Espírito Santo -Laboratório de Análise e Pesquisa em Café- LAPC, Venda Nova do Imigrante, Espírito Santo, Brasil. (lucas.pereira@ifes.edu.br).
\end{abstract}

Artigo submetido em 29/09/2020, aceito em 02/12/2020 e publicado em 23/12/2020.

Resumo: Os microrganismos atuam diretamente na qualidade da bebida do café, seja pela degradação de compostos presentes nos grãos ou pela excreção de metabólitos que difundem para o interior dos frutos. Portanto, o conhecimento dos microrganismos e seu papel na fermentação é de grande importância para se obter um produto de qualidade. A fermentação é utilizada para remover a camada de mucilagem aderida ao pergaminho do grão, com o potencial de melhoria da qualidade do café. Este 
estudo teve como objetivo avaliar a qualidade global do café em função de diferentes processamentos e tempos de fermentação. Para este estudo foram utilizados cafés cereja descascado e cafés cerejas naturais com fermentação espontânea e fermentações induzidas, nas quais foram inoculadas levedura e bactéria em tempos diferentes de fermentação. O estudo evidenciou que o uso de culturas starters durante a fermentação do café contribuiu para a obtenção de uma bebida de qualidade com características sensoriais aceitas pelos provadores, indicando que levedura Saccharomyces cerevisae em ambiente anaeróbico e sem adição de água, melhorou significativamente a qualidade sensorial da bebida.

Palavras-chave: bactéria; levedura; qualidade.

Abstract: Microorganisms act directly on the quality of the coffee cup, either by the degradation of compounds present in the beans or by the excretion of metabolites that diffuse into the coffee bean. Therefore, the knowledge of microorganisms and their role in fermentation is of great importance to obtain a quality product. Fermentation is used to remove the mucilage layer adhered to the grain parchment, with the potential to improve the quality of the coffee. This study aimed to evaluate the global quality of coffee according to different processing and fermentation times. For this study, peeled cherry coffees and natural cherries with spontaneous fermentation and induced fermentations were used, in which yeast and bacteria were inoculated at different fermentation times. The study showed that the use of starter cultures during coffee fermentation contributed to obtaining a quality drink with sensory characteristics accepted by the tasters, indicating that the yeast Saccharomyces cerevisae in an anaerobic environment and without adding water, significantly improved the sensory quality of beverage.

Keywords: bacterium; yeast; quality.

\section{INTRODUÇÃO}

A qualidade do café tem sido valorizada nos últimos anos, dando credibilidade aos cafés especiais, que se caracterizam por um conjunto de aromas equilibrados, sabores memoráveis e pela ausência de defeitos. Esses atributos estão associados à origem do café e ao genótipo cultivado (TAVEIRA et al., 2014).

Bebidas de melhor qualidade e maior valor comercial estão relacionadas as cultivares de Coffea arabica L., estes geralmente cultivados em grandes altitudes, apresentando textura do corpo suave, acidez acentuada e aromas marcantes (WINTGENS, 2004).

A complexidade da bebida é determinada principalmente pelo aroma e sabor formados durante a torra a partir de compostos químicos presentes no grão in natura, considerados precursores da qualidade (ALPIZAR et al., 2004; FARAH et al., 2005; RIBEIRO et al., 2016).
Segundo (PUERTA, 2015), a fermentação também influi na qualidade do café, e mediante a tecnologia da fermentação controlada pode-se produzir bebidas com aromas e sabores especiais, doces, cítricos e frutados, que agregam valor e consistência a qualidade do produto, porém se esse processo não for bem controlado, o mesmo pode gerar perdas na qualidade (PUERTA, 2010; PUERTA, 2013; LIN, 2010).

Os microrganismos estão naturalmente presentes na fermentação do café, influenciando na sua qualidade final, pela degradação de compostos presentes nos frutos ou pela excreção de seus produtos metabólicos (ESQUIVEL; JIMENEZ, 2012). Os frutos de café servem de substrato para o desenvolvimento de bactérias, leveduras e fungos filamentosos, suprindoos de fontes de carbono e nitrogênio, devido à sua composição química (SILVA et al., 2000).

Durante a fermentação ocorrem diferentes processos bioquímicos nos quais 
as enzimas produzidas pelas leveduras e bactérias presentes na mucilagem fermentam e degradam açucares, lipídios, proteínas e ácidos, e os convertem em álcoois, ácidos, ésteres e cetonas (RODRIGUES et al., 2017).

Diferentes tipos de processamentos e fermentações podem criar rotas metabólicas e criar aspectos sensoriais, gerando uma possibilidade de aprofundamento dos efeitos da fermentação induzida e espontânea (PEREIRA, 2017).

Assim, a adição de culturas iniciadoras ou starter, também pode ajudar a controlar o processo de fermentação, garantindo a formação de aromas e sabores desejáveis, o que aumenta a possibilidade de produzir cafés especiais (RIBEIRO et al., 2017). Contudo, novas pesquisas têm sido desenvolvidas para melhorar e controlar este processo, como também a possibilidade do uso de novas culturas starter.

Configura-se assim, a importância de aperfeiçoar o processo de agregação de qualidade do café arábica por meio de fermentações em ambiente anaeróbico. Este trabalho avaliou a influência de diferentes métodos de fermentação anaeróbica em consórcio com diferentes tempos de imersão no sistema de fermentação, com a finalidade de avaliar os impactos na construção do perfil sensorial do café.

\section{MATERIAIS E MÉTODOS}

\subsection{PROCESSAMENTO DOS CAFÉS E PREPARAÇÃO PARA FERMENTAÇÃO}

Os cafés foram selecionados da variedade Catuaí Vermelho (Coffea arabica L.), proveniente da safra 2018. O café foi colhido manualmente com auxílio de peneiras selecionando-se apenas os frutos com grau de maturação "cereja”.

Após a colheita, o café foi encaminhado para o Laboratório de análise e pesquisa em cafés (LAPC), do Instituto Federal do Espírito Santo (Ifes) - Campus Venda Nova do Imigrante - ES. Em seguida, os mesmos passaram pelo processo de lavagem, onde os cafés que flutuam na água (secos, brocados, malformados e imaturos), comumente denominados "boias", foram separados dos frutos cerejas e verdoengos.

Posteriormente, foram conduzidos cinco processamentos em café arábica natural e cereja descascado, onde os mesmos foram acondicionados em bombonas de polipropileno atóxica com capacidade de 20L devidamente higienizadas, cada qual com 2,4 kg de café.

Dos tratamentos, quatro foram realizados com fermentações induzidas e dois realizados com fermentações espontâneas:

Tratamento Levedura com água (LCA)- Foram utilizado 2,4 kg de café cereja natural e 2,4 kg de café cereja descascado, em ambos tratamentos foram adicionados $1 \%$ de levedura e água à temperatura de $42^{\circ} \mathrm{C}$, fermentados nos tempos de 36, 72, 96 e $144 \mathrm{~h}$.

Tratamento Levedura sem água (LSA)- Foram utilizado 2,4 kg de café cereja natural e 2,4 kg de café cereja descascado, em ambos tratamentos foram adicionados $1 \%$ de levedura e não houve à adição de água, fermentados nos tempos de 36, 72,96 e $144 \mathrm{~h}$.

Tratamento Bactéria com água (BCA)- Foram utilizado 2,4 kg de café cereja natural e 2,4 kg de café cereja descascado, em ambos tratamentos foram adicionados água em temperatura de $42^{\circ} \mathrm{C}$ e 400mg de bactéria láctea, fermentados nos tempos de 36, 72, 96 e $144 \mathrm{~h}$.

Tratamento Bactéria sem água (BSA)- Foram utilizado 2,4 kg de café cereja natural e 2,4 kg de café cereja descascado, em ambos tratamentos foram adicionados 400mg de bactéria láctea e não ocorreu à adição de água, fermentados nos tempos de 36, 72, 96 e $144 \mathrm{~h}$.

Tratamento Despolpado: Foi utilizado 2,4kg de café cereja descascado com adição de água em temperatura de $42^{\circ} \mathrm{C}$, fermentado nos tempos de 36, 72, 96 e $144 \mathrm{~h}$. 
Tratamento Natural: Foi utilizado 2,4kg de café cereja natural com adição de água à temperatura de $42^{\circ} \mathrm{C}$, fermentado nos tempos de 36, 72, 96 e $144 \mathrm{~h}$.

Para a fermentação com bactéria láctea, foram utilizadas 400mg do Fermento Lácteo Probiótico BioRich, contendo bifidobactérias e lactobacilos vivos. A levedura (Saccharomyces cerevisiae) comercial da marca Fleischmann ${ }^{\circledR}$, foi adquirida no mercado local e encaminhada para o laboratório, onde foi devidamente pesado 24 gramas em tubos falcon esterilizados com o auxílio da balança de precisão. Conforme recomendações propostas por Pereira (2017) para a fermentação induzida do café.

\subsection{PREPARAÇÃO DAS AMOSTRAS PARA ANÁLISE SENSORIAL}

As amostras de café foram preparadas no Laboratório de Análise e Pesquisa em Café - LAPC, do Ifes de Venda Nova do Imigrante. O processo de avaliação sensorial foi realizado seguindo a metodologia Specialty Coffee Association (SCA). As torras foram conduzidas utilizando como referência o conjunto de discos Agtron-SCAA, o ponto de torra destas amostras foi padronizado pelo disco \#60, sendo realizado entre 8 a 10 minutos. As torras foram executadas com torrador Probatino da marca Probat, respeitando a recomendação da SCA, com 24 horas de antecedência, sedo que a moagem foi realizada no momento da avaliação.

\subsection{MÉTODO DE ANÁLISE SENSORIAL DESCRITIVA COM Q-GRADERS}

Após o processo de torra, a qualidade dos cafés foi avaliada através do Protocolo para Análise Sensorial Descritiva de Café, conforme metodologia da Specialty Coffee Association - SCA (SCA, 2015), que é expressa através de uma escala numérica centesimal. O formulário de degustação fornece possibilidade de avaliação de 11 (onze) importantes atributos para o café:
Fragrância/Aroma, Uniformidade, Ausência de Defeitos (Xícara Limpa), Doçura, Sabor, Acidez, Corpo, Finalização, Equilíbrio/Balanço, Defeitos e Avaliação Global. As análises sensoriais foram realizadas por 6 Q-Graders conforme Pereira et al. (2018).

\subsection{DELINEAMENTO EXPERIMENTAL}

Os experimentos, com cafés natural e descascados, foram conduzidos no delineamento em blocos casualizados com 4 repetições no esquema de subparcelas no tempo, sendo as parcelas constituídas por 5 processamentos (Levedura com água LCA, levedura sem água - LSA, bactéria com água, BCA e bactéria sem água - BSA, e um com água - despolpado e natural) e nas subparcelas quatro tempos de fermentação - 36, 72, 96 e 144 horas.

\subsection{ANÁLISE ESTATÍSTICA}

Para as análises estatísticas, os modelos de regressão foram testados pelo teste de $\mathrm{F}$ e os coeficientes pelo teste de $\mathrm{t}$ de Student. Foram também realizadas análises de componentes principais para agrupar os processamentos em cada tempo de fermentação, mediante exames visuais em dispersões gráficas, considerando-se adequada para sua realização uma variabilidade acumulada acima de $70 \%$. Foi utilizado o programa $\mathrm{R}$ para a realização das análises estatísticas (R Core Team, 2019).

\section{RESULTADOS E DISCUSSÕES}

A nível empírico, é convencionado que a fermentação irá remover a mucilagem até a diminuição do teor de água, contribuindo assim, com a secagem dos frutos de café e gerando ganhos de qualidade. Porém, enzimas contidas nesses frutos não são suficientes para degradar completamente a mucilagem, dessa forma, se faz necessário que haja um crescimento microbiano que se possa produzir enzimas necessárias para hidrolisar a pectina 
presente na mucilagem (SILVA et al., 2013).

As principais enzimas envolvidas na fermentação do café são a poligalacturonase (PG) que catalisa a hidrólise das ligações glicosídicas $\alpha-1.4$ em ácido péctico (ácido poligalacturônico); pectina liase (PL) que atua catalisando a quebra da pectina por transeliminação, liberando ácidos galacturônicos insaturados. A terceira enzima é a pectina metilesterase (PME), responsável pela desesterificação do grupo metoxila da pectina formando ácido péctico e metanol (SILVA, 2013).

Durante a fermentação do café ocorrem diferentes processos bioquímicos, nos quais as enzimas produzidas pelas leveduras e bactérias presentes na mucilagem fermentam e degradam seus açucares, lipídios, proteínas e ácidos, e os convertem em álcoois, ácidos, ésteres e cetonas. Essas substâncias formadas alteram as características de aroma, coloração, acidez e composição do substrato (mucilagem) dos grãos de café (RODRIGUES, 2020).

Na Tabela 1, estão apresentados os resultados de qualidade global em função do tempo de fermentação para cinco métodos de processamento de café arábica, quatro com fermentação induzida e um com adição de água, para café cereja natural.

Tabela 1 - Modelos de regressão da característica qualidade global em função do tempo de fermentação e respectivos coeficientes de determinação $\mathrm{R}^{2}$, de cinco tratamentos, para o café natural.

\begin{tabular}{|c|c|c|c|c|c|c|}
\hline \multirow{2}{*}{$\begin{array}{c}\text { Tipo de } \\
\text { Fermentação }\end{array}$} & \multicolumn{4}{|c|}{ Tempo de fermentação (horas) } & \multirow{2}{*}{ Equação de regressão } & \multirow{2}{*}{$\mathrm{R}^{2}$} \\
\hline & 36 & 72 & 96 & 144 & & \\
\hline LCA & 80.5 & 83.5 & 83.3 & 83.8 & - & - \\
\hline LSA & 81.8 & 83.3 & 85.4 & 86.5 & $Y=80.2493+0.0456262 * x$ & $0.9440 *$ \\
\hline BCA & 82.2 & 79.9 & 79.6 & 82.4 & $\begin{array}{c}\mathrm{Y}=86.9844-0.165691^{* *} \mathrm{x}+ \\
0.00092793^{* *} \mathrm{x}^{2}\end{array}$ & 0.9992* \\
\hline BSA & 81.6 & 82.0 & 83.0 & 84.5 & $\mathrm{Y}=80.3333+0.0277778 * \mathrm{x}$ & $0.9317^{*}$ \\
\hline NATURAL & 80.0 & 80.0 & 79.1 & 81.0 & - & - \\
\hline
\end{tabular}

Fermentações: Levedura com água - LCA; levedura sem água - LSA; bactéria com água - BCA; bactéria sem água - BSA; natural. * e ** Significativos aos níveis de $5 \%$ e $1 \%$ de probabilidade pelos testes $\mathrm{t}$ e $\mathrm{F}$, respectivamente. Fonte: elaborado pelos autores.

Foram observados para os processamentos com BSA e LSA, relações funcionais lineares significativas entre qualidade global e tempo de fermentação, ou seja, houve um aumento da qualidade global com o tempo de fermentação, para ambas as fermentações. Para o processamento com BCA foi observada uma relação funcional quadrática significativa entre qualidade global e tempo de fermentação, ou seja, a qualidade global aumentou e alcançou o ponto de mínimo no tempo de fermentação de 89,3 horas e, a partir daí, a qualidade do café diminuiu, em relação a percepção sensorial e a partir de $144 \mathrm{~h}$ há uma tendência de aumento na qualidade global.

Mesmo não sendo observadas relações funcionais significativas entre qualidade global e tempo de fermentação nos demais processamentos, há uma tendência de estabilidade da qualidade global com o aumento do tempo de fermentação para o processamento com fermentação com água - despolpado e para o processamento LCA, observou que há uma tendência da diminuição da qualidade global até o tempo de fermentação de 72 horas e aumento a partir desse tempo.

Para a fermentação com BSA, foi possível constar que existe uma relação funcional linear significativa entre qualidade global e tempo de fermentação, ou seja, houve um aumento da qualidade global com o tempo de fermentação.

Na tabela 2, estão apresentados os resultados de qualidade global em função do tempo de fermentação para cinco processamentos por via úmida de café 
arábica, quatro com fermentação induzida e um com água, para café descascado.

Mesmo não sendo observadas relações funcionais significativas entre qualidade global e tempo de fermentação nos demais processamentos, há uma tendência de aumento da qualidade global em função do tempo de fermentação para a fermentação com LSA. Para a fermentação com LCA há uma tendência de aumento da qualidade global até o tempo de 72 horas e manutenção da qualidade até o tempo de 144 horas. Para a fermentação com água, despolpado, há uma tendência de estabilidade da qualidade global com o aumento do tempo de fermentação.
Ao observar os resultados do tratamento BCA em café natural nota-se que nos tempos de $72 \mathrm{~h}$ e $96 \mathrm{~h}$ houve um decréscimo na qualidade, e no tempo de $144 \mathrm{~h}$ houve um aumento. De acordo com os estudos de (PUERTA-QUINTERO 2015), está variação ocorre devido ao tempo de fermentação, no qual as bactérias demoraram a se adaptar ao ambiente de fermentação e promoverem a ativação de suas vias metabólicas para a geração de metabólitos nos mostos (meio) da fermentação ocorrida durante o processamento.

Tabela 2 - Modelos de regressão da característica qualidade global em função do tempo de fermentação e respectivos coeficientes de determinação $\mathrm{R}^{2}$, de cinco tratamentos, para o café descascado.

\begin{tabular}{|c|c|c|c|c|c|c|}
\hline \multirow{2}{*}{ Tratamentos } & \multicolumn{4}{|c|}{ Tempo de fermentação (horas) } & \multirow{2}{*}{ Equação de regressão } & \multirow{2}{*}{$\mathrm{R}^{2}$} \\
\hline & 36 & 72 & 96 & 144 & & \\
\hline LCA & 84.5 & 83.3 & 82.7 & 84.1 & - & \\
\hline LSA & 84.0 & 89.3 & 86.3 & 87.3 & - & \\
\hline BCA & 83.2 & 83.7 & 84.2 & 82.6 & - & \\
\hline BSA & 83.6 & 83.7 & 83.8 & 84.1 & $\mathrm{Y}=83.3645+0.00467024 *^{*} \mathrm{x}$ & $0.9317 *$ \\
\hline DESPOLPADO & 83.5 & 83.4 & 83.2 & 84.2 & - & \\
\hline
\end{tabular}

Fermentações: Levedura com água - LCA; levedura sem água - LSA; bactéria com água - BCA; bactéria sem água - BSA; despolpado. * e ** Significativos aos níveis de $5 \%$ e $1 \%$ de probabilidade pelos testes $\mathrm{t}$ e $\mathrm{F}$, respectivamente. Fonte: elaborado pelos autores.

Com os resultados apresentados nas Tabelas 1 e 2, pode-se observar para os cinco processamentos que há indícios que a qualidade do café se altera com o tempo de fermentação em condição de remoção da casca, sendo uma característica importante para o manejo e otimização dos terreiros suspensos e cobertos, no período de secagem, contribuindo para a obtenção de cafés com qualidades superiores.

No processamento BSA tanto para cereja descascado quanto para café cereja natural, foram observados um aumento na qualidade em função do tempo de fermentação. Assim como as leveduras, as bactérias também são produtoras de enzimas que durante o processamento do café hidrolisam a polpa pectinosa ao redor dos grãos e desencadeiam alterações bioquímicas que conferem sabor e cor aos grãos (LUDLOW et al., 2016). Resultados que estão também de acordo com o estudo de (PEREIRA 2016), onde o autor evidencia que a inoculação de bactéria proporcionou notas sensoriais distintas e possibilitou o aumento na qualidade da bebida.

Conforme os resultados apresentados os processamentos com inoculação de microrganismos starters são mais significativos para a qualidade do que as fermentações espontâneas, o que vai de acordo com o trabalho de (BRESSANI 2017), onde explica que na etapa de fermentante do café, vários microrganismos estão presentes, e quando este processo é conduzido de maneira espontânea, ou não controlado, pode acarretar em um café de baixa qualidade.

Para a fermentação de café cereja natural com água, despolpado, não ocorreu uma mudança no perfil sensorial, como 
demostra a Tabela 2 houve uma tendência de estabilidade da qualidade, em café cereja descascado por mais que não foi observado relações funcionais significativas, houve um aumento na qualidade, sobretudo no tempo de 144 horas, o que vai de acordo com o estudo de (GONZALEZ-RIOS et al. 2007) que afirmam que as qualidades aromáticas superiores de cafés processados por via úmida foram atribuídas ao processo de fermentação microbiana responsável pela remoção da camada de mucilagem em processamento úmido, e os resultados encontrados por Ossani et al. (2017) em estudo com provadores não treinados, perceberam complexidade e presença de notas muito exóticas em cafés naturais.

Com base na observação dos resultados obtidos, as fermentações anaeróbicas com a utilização de culturas starters com tempos acima de 72 horas, apresentaram notas globais positivas, o que demonstra que é benéfico e favorável para a qualidade da bebida a utilização dessas culturas. Este resultado diverge da observação proposta por (QUINTERO 2010), na qual a autora defende uma perda de qualidade quando o café fica em processo de fermentação, acima das 70 horas sem adição de microrganismos. Para a autora em questão, nesta condição de fermentação, os cafés apresentaram sabores e aromas azedos, fermentados, avinagrados que são desagradáveis ao paladar.

Considerando a Figura 1, tem-se a dispersão em relação aos tempos de fermentação de 36, 72, 96 e 144 horas de processamento do café cereja descascado.

Figura 1 - Diagrama de dispersão em relação aos dois primeiros componentes principais dos processamentos: Levedura com água - LCA, levedura sem água - LSA, bactéria com água -

BCA, bactéria sem água - BSA e despolpado - W, em café descascado fermentado por 36 horas (A); por 72 horas (B); por 96 horas (C); e, por 144 horas (D).

A

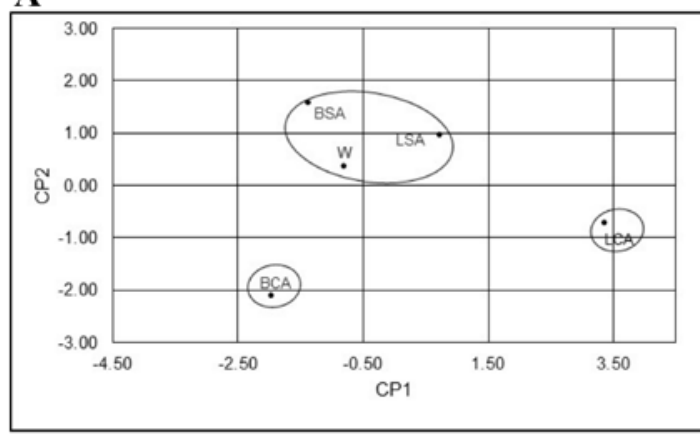

C

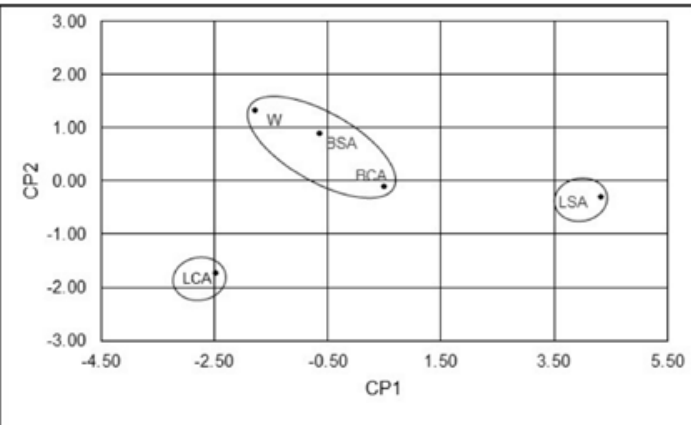

B

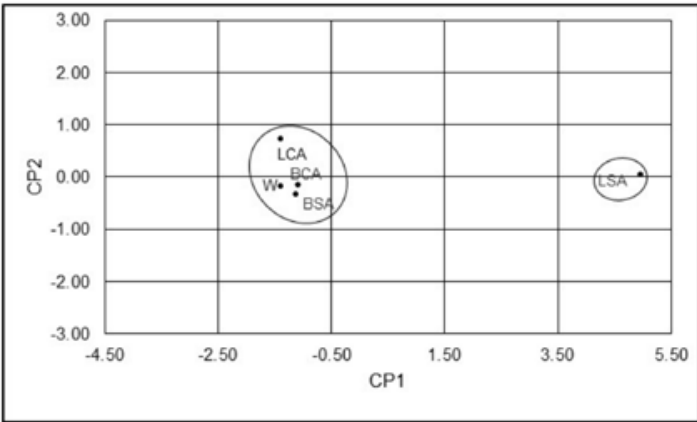

D

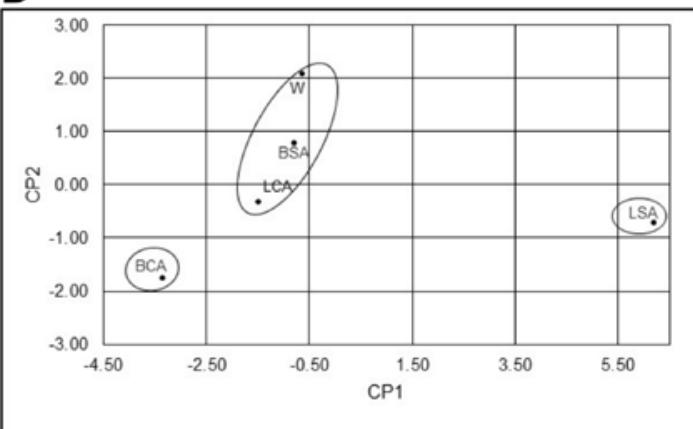

Fonte: elaborado pelos autores.

$\mathrm{Na}$ Figura 1A (tempo de fermentação de $36 \mathrm{~h}$ ), tem-se a dispersão dos tratamentos com base nas respectivas coordenadas relativas aos dois primeiros componentes principais, CP1 e CP2 com percentagem simples de $57,06 \%$ e $26,60 \%$ 
respectivamente, em que os processamentos com fermentações por 36 horas com BSA, LSA e $\mathrm{W}$ formam o primeiro grupo, o processamento com BCA forma o segundo grupo e o com LCA o terceiro grupo, e que os dois componentes absorveram 83,66\% da variação existentes nas características originais.

Em relação ao tempo de fermentação de 72 h (Figura 1B), CP1 e $\mathrm{CP} 2$, apresentaram percentagem simples de $96,77 \%$ e $2,16 \%$ respectivamente, onde BSA, LCA, BCA e $W$ formaram o primeiro grupo e o processamento com LSA formou o segundo grupo, e que os dois componentes absorveram 98,93\% da variação existentes nas características originais. Para o tempo de fermentação de 96 h (Figura 1C), CP1 e CP2 com percentagem simples de $79,56 \%$ e $15,59 \%$ respectivamente, em que os processamentos com fermentações de $96 \mathrm{~h}$ com BSA, BCA e $\mathrm{W}$ formaram o primeiro grupo, o processamento com LCA formou o segundo grupo e o processamento LSA formou o terceiro grupo, e que os dois componentes absorveram 95,15\% da variação existentes nas características originais.

Finalmente, para o tempo de fermentação de 144 h (Figura 1D, CP1 e CP2 com percentagem simples de $82,57 \%$ e $13,1 \%$ respectivamente, em que os processamentos com fermentações com BSA, LCA e $\mathrm{W}$ formaram o primeiro grupo, o processamento com LSA formou o segundo grupo e o processamento BCA formou o terceiro grupo, e que os dois componentes absorveram 95,98\% da variação existentes nas características originais.
Considerando a Figura 2, tem-se a dispersão em relação aos tempos de fermentação de 36, 72, 96 e 144 horas de processamento do café cereja natural.

No processamento do café cereja natural com fermentação durante $36 \mathrm{~h}$ (Figura 2A), CP1 e CP2 apresentaram percentagem simples de $74,85 \%$ e $15,10 \%$, em que BSA e LSA formaram o primeiro grupo, o processamento com LCA formou o segundo grupo, o processamento com fermentação com água formou o terceiro grupo e o processamento com BCA formou o último grupo. Os dois componentes representaram 89,95\% da variação existentes nas características originais.

Para o período de fermentação de 72 h (Figura 2B), CP1 e CP2 com percentagem simples de $85,71 \%$ e $9,74 \%$ respectivamente, com LCA e LSA formaram o primeiro grupo, os processamentos com BCA e W formaram o segundo grupo e o processamento com fermentação com BSA formou o terceiro grupo, e que os dois componentes expressaram 95,45\% da variação existentes nas características originais.

No tempo de fermentação de $96 \mathrm{~h}$ (Figura 2C), CP1 e CP2 representaram $94,52 \%$ e $3,53 \%$ da variação total, respectivamente. Os tratamentos LCA e BSA formaram o primeiro grupo, os processamentos com BCA e W formaram o segundo grupo e o processamento com fermentação com LSA formou o terceiro grupo. Os dois componentes expressaram $98,05 \%$ da variação total observada. 
Figura 2 - Diagrama de dispersão em relação aos dois primeiros componentes principais dos processamentos: Levedura com água - LCA, levedura sem água - LSA, bactéria com água BCA, bactéria sem água - BSA e natural - W, em café natural fermentado por 36 horas (A); por 72 horas (B); por 96 horas (C); e, por 144 horas (D).

A

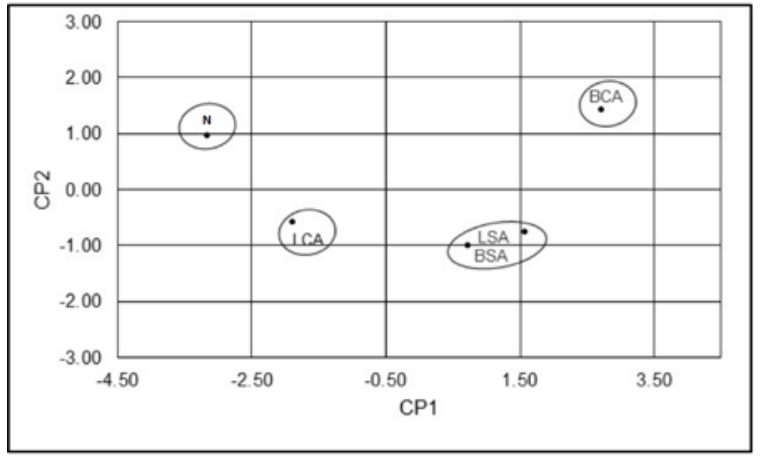

C

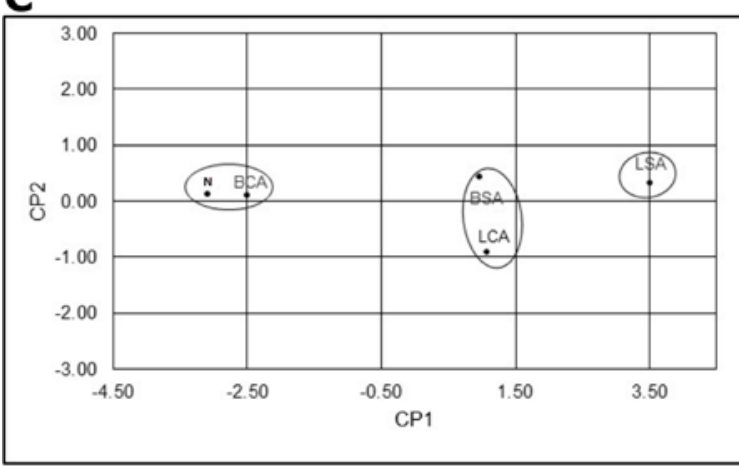

Fonte: elaborado pelos autores

Por fim, para o tempo de fermentação de 144 h (Figura 2D), os componentes CP1 e CP2 apresentaram $92,83 \%$ e $4,54 \%$ da variação, respectivamente. Os tratamentos LCA, BCA BSA formaram o primeiro grupo, LSA formou o segundo grupo e o processamento com $\mathrm{W}$ formou o terceiro grupo. Os dois componentes expressaram $97,37 \%$ da variação total observada.

Os resultados apresentados nos componentes principais da Figura de 1 , mostram os agrupamentos dos cinco processamentos em cafés descascados, e foi observado que não há agrupamento uniforme dos processamentos em relação aos tempos de fermentação, exceto, para o processamento com levedura sem água LSA que se manteve isolado a partir do tempo de 72 horas de fermentação, e coincidentemente, foi o processamento que alcançou as maiores notas de qualidade
B

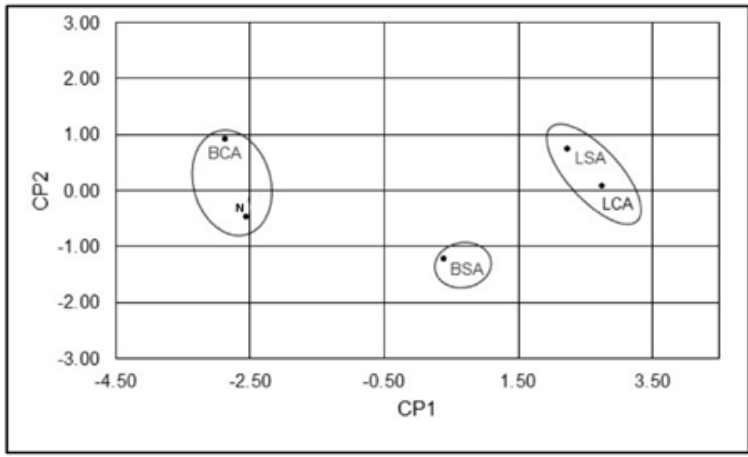

D

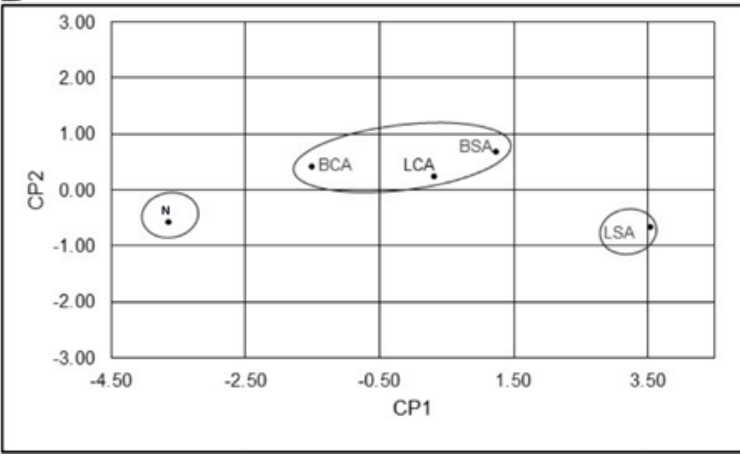

global para cafés descascados, a partir desse tempo de fermentação.

Para o café natural, a Figura 2 mostrou também que não há agrupamento uniforme dos processamentos em relação ao tempo de fermentação, exceto para o processamento com levedura sem água LSA, que se manteve isolados dos demais processamentos a partir do tempo de fermentação de 96 horas, conferindo as maiores pontuações de qualidade global em relação às demais fermentações nos tempos de 96 e 144 horas.

Na Figura 2B houve o agrupamento dos tratamentos LSA e LCA corroborando com os resultados encontrados por Pereira et al. (2014) que relataram que após uma inoculação bem sucedida de microrganismos durante a fermentação dos grãos de café, a capacidade das leveduras de se adaptarem e enfrentarem o ambiente inóspito e as condições estressantes no meio fermentante é de grande importância 
para o desempenho da fermentação, tendo em vista a participação desse grupo microbiano na melhoria das características do café.

Estes resultados estão de acordo com os resultados de (FREIRAS et. al., 2018), o processamento por via úmida empregado de forma adequada foi suficiente para obtenção de uma bebida de qualidade, principalmente quando utilizados os inóculos, que produziram quantidades diferentes de compostos que possivelmente incrementaram a bebida.

Em contrapartida, os cafés naturais originam bebidas mais doces e encorpadas por possuírem maiores teores de açúcares e sólidos solúveis (KNOPP; BYTOF; SELMAR, 2006), contribuindo para o aumento na doçura do café e consequentemente o aumento do corpo da bebida.

Os resultados obtidos por análises de componentes principais mostram que não há agrupamentos uniformes dos processamentos nos tempos de fermentação, várias hipóteses surgem para poder justificar tais resultados, uma delas seria a subjetividade da análise sensorial, uma vez que se trata de uma análise que depende de experiência e sensibilidade, como explica o estudo de (PEREIRA et al., 2018.) Ou que painéis sensoriais com consumidores sejam mais promissores para compreender de fato as melhores estratégias para definição de ações com fermentações mais intensas.

Conforme os resultados apresentados nas tabelas e nas figuras, pode-se observar que o tratamento LSA tanto para cafés cereja descascados quanto para cafés cereja naturais, apresentaram melhores resultados em comparação aos demais tratamentos, confirmando que a escolha da forma de processamento deve ser considerada na estratégia de desenvolvimento dos perfis sensoriais (BYTOF et al., 2005; KNOPP; BYTOF; SELMAR, 2006). Além disso, de acordo com Freitas (2018) a Sacharomicyes cerevisiae possui grande potencial para uso como cultura starter no processamento de via úmida do café, devido à possibilidade de ajudar a controlar e padronizar o processo de fermentação e produzir bebidas com características sensoriais diferenciadas. Com o consumo dos nutrientes e do oxigênio e a formação do álcool, a Saccharomyces torna o ambiente de fermentação seletivo.

Como não foi realizada a quantificação físico-química do mosto de fermentação, as oscilações observadas entre os parâmetros sensoriais indicam que as discussões propostas por (LIN 2010), relativo ao controle de temperatura, espessura da camada de mucilagem, concentrações de enzima e microrganismos podem oscilar no tempo da fermentação. Isso indica assim, uma real necessidade de controle destes parâmetros no processo de fermentação.

\section{CONCLUSÃO}

Através dos experimentos realizados, é notório que a inoculação de levedura Saccharomyces cerevisae em ambiente anaeróbico e sem adição de água, melhorou significativamente a qualidade sensorial da bebida.

Por mais que o processamento despolpado em cereja descascado tenha obtido qualidade global nos tempos de 36 e 144 horas de fermentação, não foi possível estimar uma equação de regressão significativa.

A utilização de bactéria em meio anaeróbico contribuiu para o acréscimo da qualidade global em função do tempo de fermentação. Com o emprego de água, fermentações em cafés naturais com mais de 89,3 horas não foram aceitas sensorialmente pelos provadores.

Com base nos resultados pode-se notar que com a inoculação de microrganismos em processamentos de café cereja natural melhora a qualidade do café. 


\section{AGRADECIMENTOS}

Os autores agradecem à Cooperativa de Crédito Livre Admissão Sul Serrana do Espírito Santo - Sicoob (23186000886201801), à Coordenação de Aperfeiçoamento de Pessoal de Nível Superior - CAPES e ao Conselho Nacional de Desenvolvimento Científico e Tecnológico - CNPq, ao Instituto Federal do Espírito Santo, pelo apoio a pesquisa, por meio do edital PRPPG n ${ }^{0}$. 10/2019 Programa Pesquisador Produtividade PPP, e ao Instituto Capixaba de Pesquisa, Assistência Técnica e Extensão - Incaper, pela cooperação com todos os atores no suporte e desenvolvimento deste estudo.

\section{REFERÊNCIAS}

ALPIZAR, Edgardo; BERTRAND, Benoît. Incidência de elevação na composição química e qualidade da bebida do café na América Central. In: 20 ${ }^{\text {a }}$ Conferência Internacional sobre a Ciência do Café . 2004. p. 11-15.

BRESSANI, Ana Paula Pereira. Avaliação química e sensorial de café catuaí amarelo fermentado pelo processamento por via seca com inoculação de leveduras. 2017.

BYTOF, G. et al. Influence of processing on the generation of -aminobutyric acid in green beans. European Food Research and Technology, Berlin, v. 220, n. 3/4, p. 245-250, Mar. 2005.

DE MELO PEREIRA, Gilberto Vinícius et al. Isolation, selection and evaluation of yeasts for use in fermentation of coffee beans by the wet process. International journal of food microbiology, v. 188, p. 60-66, 2014.

ESQUIVEL, Patricia; JIMÉNEZ, Víctor M. Functional properties of coffee and coffee byproducts. Food Research International, v. 46, n. 2, p. 488-495, 2012.

FARAH, A. et al. Effect of Roasting on the Formation of Chlorogenic Acid Lactones in Coffee. Journal of Agricultural and Food Chemistry, Washington, v. 53, n. 5, p. 1105-
1113, Feb. 2005

FREITAS, Valdeir Viana. Avaliação da fermentação do café arábica com uso de culturas starters. 2018.

GONZÁLEZ-RÍOS, O. et al. Impact of "ecological" post-harvest processing on the volatile fraction of coffee beans: I. Green coffee. Journal of Food Composition and Analysis, v. 20, p. 289-296, 2007.

KNOPP, Sven; BYTOF, Gerhard; SELMAR, Dirk. Influence of processing on the content of sugars in green Arabica coffee beans. European Food Research and Technology, v. 223, n. 2, p. 195, 2006.

LIN, C. C. Approach of Improving Coffee Industry in Taiwan-Promote Quality of Coffee Bean by Fermentation. The Journal of International Management Studies, v. 5, n. 1, April 2010.

LUDLOW, Catherine L. et al. Independent origins of yeast associated with coffee and cacao fermentation. Current Biology, v. 26, n. 7, p. 965-971, 2016.

OSSANI, P. C.; CIRILLO, M. Â.; BORÉM, F. M.; RIBEIRO, D. E.; CORTEZ, R. M. Qualidade de cafés especiais: Uma avaliação sensorial feita com consumidores utilizando a técnica MFACT. Revista Ciencia Agronomica, v. 48, n. 1, p. 92-100, 2017.

PEREIRA, Gilberto Vinícius de Melo et al. Potential of lactic acid bacteria to improve the fermentation and quality of coffee during on-farm processing. International Journal of Food Science \& Technology, v. 51, n. 7, p. 1689-1695, 2016.

PEREIRA, Lucas L. et al. Propositions on the Optimal Number of Q-Graders and R-Graders. Journal of Food Quality, v. 2018, p. 1-7, 2018. Disponível em:

https://www.hindawi.com/journals/jfq/2018/32 85452/. Acesso em: 10 setembro 2020.

PEREIRA, Lucas L. Novas abordagens para produção de cafés especiais a partir do processamento via-úmida. Tese (Doutorado em Engenharia de Produção) - Universidade 
Federal do Rio Grande do Sul, Porto Alegre 2017.

PUERTA, G. I. Factores procesos y controles en la fermentación del café. Centro Nacional de Investigaciones de Café (Cenicafé), 2013. PUERTA, Q. G. I. Fermentación controlada del café: Tecnología para agregar valor a la calidad. Cenicafé, Chinchiná, 2015. 12 p. (Avances Técnicos No. 454).

PUERTA, Q. G. I. Fundamentos del proceso de fermentación en el beneficio del café. Cenicafé, Chinchiná, 2010. 12 p. (Avances Técnicos No. 402).

PUERTA, G. I. Cinética química de la fermentación del mucílago de café a temperatura ambiente. 2015.

R CORE TEAM. R: A language and environment for statistical computing. Viena, Áustria: R Foundation for Statistical Computing. Disponível em: <https://www.Rproject.org>.Accessed: 28 August 2019.

RIBEIRO, D. E. et al. Interaction of genotype, environment and processing in the chemical composition expression and sensorial quality of Arabica coffee. African Journal of Agricultural Research, Ebene, v. 11, n. 27, p. 2412-2422, July 2016.

RIBEIRO, Luciana Silva et al. Controlled fermentation of semi-dry coffee (Coffea arabica) using starter cultures: A sensory perspective. LWT - Food Science and Technology, v. 82, p. 32-38, 2017.

RODRIGUES, G. Z. et al. Avaliação do processo de fermentação controlada do café em diferentes condições de tempo, temperatura e umidade. 2017.

RODRIGUES, Guilherme Zatti; DA CUNHA, Luciane Tavares; ALMEIDA, Gustavo Rennó Reis. Desenvolvimento e validação da fermentação controlada de frutos do café no pós-colheita em diferentes tempos. Revista Agroveterinária do Sul de Minas, v. 2, n. 1, p. 45-52, 2020.

SELMAR, D.; BYTOF, G.; KNOPP, S. E. The storage of green coffee (Coffea arabica): Decrease of viability and changes of potential aroma precursors. Annals of Botany, v. 101, n. 1, p. 31-38, 2008.
SILVA, Cristina F. et al. Microbial diversity during maturation and natural processing of coffee cherries of Coffea arabica in Brazil. International journal of food microbiology, v. 60, n. 2-3, p. 251-260, 2000. SILVA, Cristina Ferreira et al. Evaluation of a potential starter culture for enhance quality of coffee fermentation. World Journal of Microbiology and Biotechnology, v. 29, n. 2, p. 235-247, 2013.

\section{SPECIALTY COFFEE ASSOCIATION OF AMERICA. SCAA Protocols: Cupping Specialty Coffee. SCAA, 2015.}

TAVEIRA, José Henrique da Silva. Metabolite profile and sensory quality of arabica genotypes grown in different altitudes and processed by different postharvest methods. 2014. $71 \mathrm{f}$ Tese (Doutorado) - Universidade Federal de Lavras, Lavras, 2014.

WINTGENS, Jean Nicolas. Coffee: Growing, Processing, Sustainable Environment. International Journal of Food Science and Technology, v. 40, n. 6, p. 683-687, 2004. Disponívelhttp://doi.wiley.com/10.1111/j.1365 -2621.2005.00988.x. Acesso em: 10 setembro 2019 